\title{
QUALIDADE SENSORIAL DE FRUTOS DE HÍBRIDOS DE BANANEIRA CULTIVAR PACOVAN ${ }^{1}$
}

\author{
FERNANDO CÉSAR AKIRA URBANO MATSUURA²; RICARDO LUÍS CARDOSO³; DÁRIO ELOY RIBEIRO ${ }^{4}$
}

\begin{abstract}
RESUMO - O objetivo desse experimento foi avaliar a aceitação sensorial dos híbridos PV03-44 e PV03-76, provenientes do parental feminino cultivar Pacovan e selecionados pela Embrapa Mandioca e Fruticultura. Os atributos aroma, sabor, textura e cor foram avaliados por meio de teste de aceitação, utilizando-se de escala hedônica de 9 pontos, com frutos servidos na forma de rodelas de 1,5 $\mathrm{cm}$ de espessura. Análises de $\mathrm{pH}$, sólidos solúveis totais, acidez total titulável, açúcares totais e redutores e amido também foram realizadas. Os frutos apresentaram valores de $\mathrm{pH}$ na faixa de 4,3 a 4,5, acidez total titulável (\% ácido málico) de 0,53 a 0,64 , sólidos solúveis totais (\%) de 22,2 a 27,4, açúcares totais (\%) de 15,0 a 24,3, açúcares redutores (\%) de 10,7 a 12,4 e amido (\%) de 2,1 a 3,2. Os resultados da análise sensorial mostraram os maiores valores para a cultivar Pacovan quanto aos atributos de sabor, textura e cor, com valores de 7,0; 6,8 e 7,8, respectivamente, posicionando-se entre os termos "gostei regularmente" e "gostei muito", na escala hedônica de 9 pontos. Os híbridos PV03-76 e PV03-44 apresentaram resultados similares entre si e significativamente inferiores aos da cultivar Pacovan para os atributos sabor e cor. Conclui-se pela aceitação sensorial satisfatória, exceto para o atributo cor, dos híbridos PV0344 e PV03-76.
\end{abstract}

Termos para indexação: banana, Musa spp., aroma, sabor, textura, cor

\section{SENSORIAL QUALITY OF BANANA FRUITS FROM HYBRIDS OF PACOVAN CULTIVAR}

ABSTRACT - This work aimed to evaluate the sensory acceptance of PV03-44 and PV03-76 hybrids obtained from the Pacovan cultivar, selected at Embrapa Cassava and Tropical Fruit Crops. The odor, flavor, texture and color attributes were evaluated, using the acceptance test (9-point hedonic scale). Fruit samples were evaluated as $1.5 \mathrm{~cm}$ thick slices. Analyses of $\mathrm{pH}$, total soluble solids, total titratable acidity, total and reducing sugars and starch contents were carried out. The fruits showed values from 4.3 to 4.5 for $\mathrm{pH}$, 22.2 to $27.4 \%$ for total soluble solids, 0.53 to $0.64 \%$ for total titratable acidity, 15.0 to $24.3 \%$ for total sugars, 10.7 to $12.4 \%$ for reducing sugars, and 2.1 to $3.2 \%$ for starch content. The results of sensorial analyses of the Pacovan cultivar showed higher values for flavor, texture and color (7.0, 6.8 and 7.8, respectively). The PV03-76 and PV03-44 hybrids presented similar results, which were lower than the Pacovan cultivar for flavor and color attributes. The fruits of the hybrids studied have regular sensorial acceptance, except for the color.

Index terms: banana, Musa spp., odor, flavor, texture, color

As bananas são frutos comestíveis do gênero Musa spp., cultivadas na maioria dos países tropicais, em área superior a quatro milhões de hectares, gerando uma produção aproximada de 76 milhões de toneladas (Alves, 1999).

O Brasil produziu cerca de 5,6 milhões de toneladas em 1999 (FAO, 2000) e, embora a bananeira seja cultivada de norte a sul do País, $99 \%$ da produção é destinada ao mercado interno (Alves, 1999; Borges et al., 1997).

Por ser considerada uma das frutas mais apreciadas pelos consumidores brasileiros (Embrapa, 1995), uma série de pesquisas ligadas ao melhoramento genético vem se realizando, incluindo a obtenção de híbridos tetraplóides, a partir de triplóides comerciais com diplóides melhorados, com o objetivo de se reunir características de resistência/tolerância a pragas e doenças, obter plantas de boa produtividade, com porte médio a baixo e frutos de qualidade superior (Dantas et al., 1993).

O programa de melhoramento genético da Embrapa Mandioca e Fruticultura selecionou dois híbridos tetraplóides ('PV03-44' e 'PV03-76') provenientes do cruzamento entre 'Pacovan' (triplóide) e 'Calcutta' (diplóide), cuja principal característica é a resistência a doenças, como Sigatoca-amarela e mal-do-Panamá (Dantas et al., 1993; Embrapa, 1994; Borges et al., 1997; Alves, 1999). Esta resistência implica redução no uso de defensivos agrícolas nas plantações, diminuindo as despesas e, principalmente, os danos ao meio ambiente. As cultivares Pacovan e Prata são responsáveis por aproximadamente $60 \%$ da

1 (Trabalho 072/2001). Recebido: 27/03/2001. Aceito para publicação: 01/11/2001.

2 Pesquisador, Tecnologia de alimentos, Embrapa Mandioca e Fruticultura, Laboratório de Ciência e Tecnologia de Alimentos. Caixa Postal 007, 44380-000, Cruz das Almas, BA. (75) 621-8049 fersaopaulo@zipmail.com.br

3 Professor, Tecnologia de alimentos, Escola de Agronomia da Universidade Federal da Bahia (AGRUFBA), Departamento de Química Agrícola, 44380-000, Cruz das Almas, BA. T: (75) 721-1220/ricardos@ufba.br

4 Engenheiro Agrônomo. Mestre em Fruticultura pela Escola de Agronomia da Universidade Federal da Bahia (GRUFBA), Cruz das Almas/BA. T: (75) $721-1220$ 
área cultivada com banana no Brasil (Oliveira \& Silva et al., 1999).

A análise sensorial de frutos das cultivares e híbridos de plantas deve ser realizada a fim de se verificar a aceitação dos mesmos por parte dos consumidores. Essa análise é feita mediante a utilização dos sentidos humanos: visão, gustação, olfato, audição e sensibilidade-cutânea. Desta forma, as sensações que resultam da interação dos órgãos humanos dos sentidos com os alimentos são usadas para avaliar sua qualidade, aceitabilidade por parte do consumidor e nas pesquisas para o desenvolvimento de novos produtos (Teixeira et al., 1987; Moraes, 1988).

Os atributos sensoriais, como aroma, sabor, textura e cor, são influenciados significativamente pela composição química e, nos frutos de bananeira, principalmente pelos ácidos, açúcares e compostos fenólicos (Soto Ballestero, 1992). Transformações ocorrem durante o amadurecimento da banana, principalmente no amido, açúcares, acidez, $\mathrm{pH}$, sólidos solúveis totais e taninos (Lal et al., 1974). Nessa etapa, tem-se aumento no teor de açúcares simples, diminuição na de ácidos simples e orgânicos e no de compostos fenólicos, acarretando em redução na adstringência e acidez, além da liberação de substâncias voláteis, fatores responsáveis pelo aroma e sabor, que são características fundamentais para a aceitação da fruta (Soto Ballestero, 1992). A acidez em frutos de bananeira varia de $0,17 \%$ a $0,67 \%$ (Fernandes et al., 1979; Rossignoli, 1983), o pH, de 4,2 a 4,8 (Soto Ballestero, 1992), e o teor de sólidos solúveis totais aumenta até um máximo de $27 \%$, tendo uma pequena diminuição quando a fruta já está muito madura (Bleinroth, 1995).

Este trabalho teve como objetivo avaliar sensorialmente frutos maduros dos híbridos 'PV03-44' e 'PV03-76' e da cultivar Pacovan.

As matérias-primas utilizadas foram frutos dos híbridos PV03-44 e PV03-76, selecionados pelo programa de melhoramento genético da bananeira da Embrapa Mandioca e Fruticultura, e da cultivar Pacovan, parental feminino daqueles híbridos, e uma das variedades mais cultivadas no Brasil.

A cultivar Pacovan é um triplóide, pertencente ao grupo genômico $\mathrm{AAB}$, sendo uma mutação da 'Prata'. A planta é vigorosa, com porte alto, e tem superado, em quase $100 \%$, a produtividade da 'Prata'. É moderadamente suscetível ao maldo-Panamá, suscetível às Sigatocas-amarela e negra, e ao moco, resistente a nematóides e moderadamente resistente à broca-dorizoma (Embrapa, 1994; Borges et al., 1997). Ambos os híbridos são pertencentes ao grupo genômico $\mathrm{AAAB}$, tetraplóides oriundos do cruzamento entre 'Pacovan' (triplóide) e 'Calcutta' (diplóide) e com resistência à Sigatoca-amarela. O 'PV03-44' possui porte médio a alto, produtividade regular e resistência ao mal-do-Panamá, enquanto o 'PV03-76' apresenta porte alto, moderada resistência ao mal-do-Panamá e nível de produtividade similar ou superior à da 'Pacovan' (Dantas et al., 1993; Alves, 1999).

As plantações da cultivar e dos híbridos foram realizadas na Embrapa Mandioca e Fruticultura, conduzidas segundo as recomendações técnicas usuais, em delineamento inteiramente casualizado, com 13 repetições (uma planta por repetição). Foram utilizados três cachos de material, colhidos no estádio de desenvolvimento equivalente a " $3 / 4$ gordo", de forma aleatória. Cinco pencas de cada cacho foram escolhidas ao acaso, evitandose as pencas das extremidades do cacho. Os frutos foram analisados no ponto adequado de consumo, isto é, quando não mais apresentavam sabor adstringente (pedaços da polpa eram degustados diariamente para a verificação de ausência de adstringência e, também, imediatamente antes do preparo das amostras servidas aos provadores para confirmação).

A análise sensorial avaliou a aceitação dos atributos aroma, sabor, textura e cor da polpa, usando-se escala hedônica de 9 pontos, com extremidades denominadas desgostei muitíssimo (1) e gostei muitíssimo (9) (Moraes, 1988). Os frutos foram servidos na quantidade de três rodelas de cada cultivar ou híbrido, por provador, cuja espessura era de $1,5 \mathrm{~cm}$ (evitando-se as extremidades dos dedos), a 30 provadores não treinados. Os testes foram realizados em cabines individuais com iluminação adequada.

As análises físico-químicas foram feitas avaliando-se o pH (leitura direta em potenciômetro); acidez total titulável (A.O.A.C., 1984); sólidos solúveis totais (leitura direta em refratômetro); açúcares totais e redutores (método titulométrico - Instituto Adolfo Lutz, 1976); açúcares não redutores (pela diferença entre açúcares totais e redutores) e amido (A.O.A.C., 1984) e objetivando averiguar o ponto de consumo dos frutos utilizados.

Os valores da análise sensorial foram analisados como delineamento inteiramente casualizado, considerando a cultivar e os híbridos como fatores de variação, e submetidos à análise de variância, teste $\mathrm{F}$, e de comparação de médias, teste Tukey, a nível de 5\% (Gomes, 1973).

Os resultados da análise sensorial mostraram não existir diferença significativa $(\mathrm{p}>0,05)$ entre os valores obtidos pelos híbridos PV03-44 e PV03-76 em relação a todos os atributos avaliados, aroma, sabor, textura e cor (Figura 1). Para todos os atributos, exceto para a cor, os híbridos obtiveram valores entre 6,0 ("gostei ligeiramente") e 7,0 ("gostei regularmente"); portanto, com aceitação sensorial satisfatória. No entanto, a aceitação sensorial dos híbridos foi inferior àquela da cultivar Pacovan, que obteve valores sensoriais mais altos para três dos quatro atributos avaliados, podendo ser classificada como produto de elevada aceitação sensorial (Figura 1).

Quanto aos atributos aroma e textura, os híbridos e a

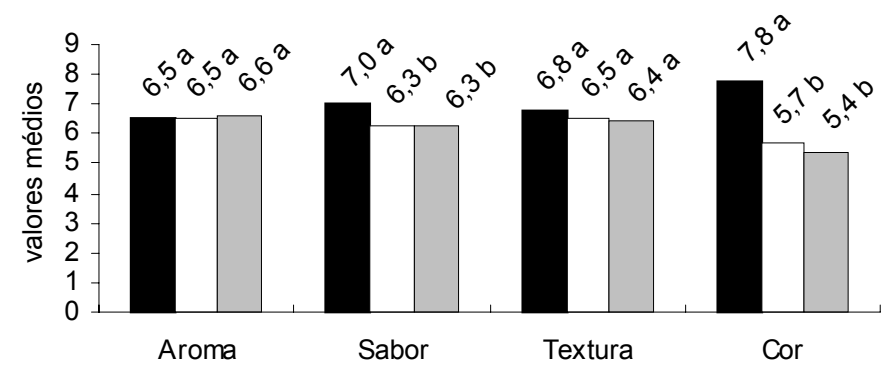

Pacovan $\square$ PV03-44 $\square$ PV03-76

Médias seguidas de mesma letra, em cada atributo, não diferem significativamente a nível de $5 \%$, pelo teste de Tukey

FIGURA 1 - Valores médios para os atributos de aroma, sabor, textura e cor da polpa dos frutos de bananeira dos híbridos PV03-44 e PV03-76 e da cultivar Pacovan. Embrapa Mandioca e Fruticultura. Cruz das Almas, 1997. 
cultivar não diferiram significativamente $(\mathrm{p}>0,05)$, com todos obtendo valores de aceitação satisfatórios.

A superioridade da 'Pacovan' quanto à aceitação foi significativa para os atributos sabor e cor (Figura 1). A cultivar Pacovan apresentou valor médio 7,0 para o sabor e próximo a 8,0 ("gostei muito") para a cor. Os híbridos apresentaram valores próximos a 6,0 para o sabor e entre 5,0 ("nem gostei, nem desgostei") e 6,0 para a cor, mostrando satisfatória aceitação sensorial para sabor e baixa aceitação em relação à cor. Salientase que, no conjunto dos atributos avaliados, o sabor e a cor são de fundamental importância. A cor, por estar ligada à atratividade para o consumidor, e o sabor, por se relacionar com a preferência pela variedade, a exemplo da banana-maçã e da banana-ouro.

Todos os resultados das análises físico-químicas apresentaram valores considerados normais para frutos maduros (Tabela 1), com pH variando de 4,3 a 4,5, teor de sólidos solúveis totais de 22,2 a $28,3 \%$, acidez total titulável de 0,52 a $0,64 \%$, açúcares totais de 15,4 a $25,0 \%$ e teor de amido de 2,1 a 3,2\%, os quais são concordantes com os encontrados por Bleinroth (1995), Soto Ballestero (1992), Rossignoli (1983) e Fernandes et al. (1979). O híbrido PV03-76 apresentou os menores teores de sólidos solúveis totais $(22,2 \%)$ e açúcares totais $(15,4 \%)$. Apesar da elevada diferença encontrada no teor de açúcares totais entre os híbridos, a mesma não teve influência na avaliação sensorial do atributo sabor (Figura 1). O parental feminino 'Pacovan' apresentou os maiores teores de sólidos solúveis totais $(28,3 \%)$ e açúcares totais $(25,0 \%)$.

TABELA 1 - Valores médios de parâmetros físico-químicos da polpa dos frutos de bananeira dos híbridos PV0344 e PV03-76 e da cultivar Pacovan. Embrapa Mandioca e Fruticultura. Cruz das Almas, 1997.

\begin{tabular}{lccc}
\hline \multirow{2}{*}{ Parâmetros } & \multicolumn{3}{c}{ Cultivar e Híbridos* } \\
\cline { 2 - 4 } & Pacovan & PV03-44 & PV03-76 \\
\hline PH & 4,3 & 4,4 & 4,5 \\
Sólidos Solúveis Totais (\%) & 28,3 & 27,4 & 22,2 \\
Acidez Total Titulável $\quad(\%$ ác. & 0,64 & 0,53 & 0,52 \\
málico) & & & \\
Açúcares Totais (\%, p/p) & 25,0 & 24,3 & 15,4 \\
Açúcares Redutores (\%, p/p) & 11,6 & 10,7 & 11,8 \\
Açúcares Não Redutores (\%, p/p) & 13,4 & 13,6 & 3,6 \\
Amido (\%, p/p) & 3,2 & 2,2 & 2,1 \\
\hline
\end{tabular}

*: Média de 03 amostras

Concluiu-se que os híbridos PV03-44 e PV03-76 obtiveram aceitação sensorial satisfatória (exceto para a cor) e similar entre si, porém esta aceitação foi inferior à da cultivar Pacovan, parental feminino de ambos os híbridos.

\section{AGRADECIMENTO}

Ao pesquisador Sebastião de Oliveira e Silva, da Embrapa Mandioca e Fruticultura, pelo fornecimento dos frutos dos híbridos de bananeira.

\section{REFERÊNCIAS BIBLIOGRÁFICAS}

ALVES, E. J (Org.). A cultura da banana: aspectos técnicos, socioeconômicos e agroindustriais. 2.ed. Brasília: Embrapa-SPI / Cruz das Almas: Embrapa - CNPMF, 1999. 585p.

A. O. A. C(Associaton of Official Analytical Chemists). Official methods of analysis. 14. ed. Arlington: 1984. 1141p.

BLEINROTH, E. W. Matéria-Prima. In: INSTITUTO DE TECNOLOGIA DE ALIMENTOS. Banana - Matéria-Prima, processamento e aspectos econômicos. 2.ed. Campinas: ITAL, p.133-196, 1995.

BORGES, A. L.; ALVES, E. J.; SILVA, S. de O. e; SOUZA, L. da S.; MATOS, A. P. de; FANCELLI, M.; OLIVEIRA, A M. G.; CORDEIRO, Z. J. M.; SILVEIRA, J. R. S.; COSTA, D. da C.; MEDINA, V. M.; OLIVEIRA, S. L. de; SOUZA, J. da S.; OLIVEIRA, R. P. de; CARDOSO, C. E. L.; MATSUURA, F. C. A. U.; ALMEIDA, C. O. de. O cultivo da banana. Cruz das Almas: EMBRAPA-CNPMF, 1997. 109p. (Circular Técnica, 27).

DANTAS, J. L. L.; SHEPHERD, K. L.; SOARES FILHO, W. dos S., CORDEIRO, Z. J. M.; SILVA, S. de O.; SOUZA, A. da S. Citogenética e melhoramento genético da bananeira (Musa spp.). Cruz das Almas: EMBRAPA-CNPMF, 1993. 61p. (Documentos, 48).

EMBRAPA. Centro Nacional de Pesquisa de Mandioca e Fruticultura Tropical (Cruz das Almas, BA). Banana para exportação: aspectos técnicos da produção. Cruz das Almas: MAARA-SDR-FRUPEX/EMBRAPA-CNPMF/EMBRAPA-SPI, 1995. 106p. (FRUPEX. Publicações Técnicas, 18).

EMBRAPA. A cultura da banana. Brasília: Embrapa-SPI, 1994. 97p. (Coleção Plantar, 16).

FAO. Disponível: site FAO (01/03/2000). url: http://www.fao.org/ foodstat.html. Acesso em 8 de março 2000.

FERNANDES, K. M.; CARVALHO, V. D. de; CAL-VIDAL, J. Physical changes during ripening of silver bananas. Journal of Food Science, Chicago, v.44, n.4, p.1254-1255, 1979.

GOMES, F. P. Curso de Estatística Experimental. 5.ed. Piracicaba: Nobel, 1973.468p.

INSTITUTO ADOLFO LUTZ. Normas analíticas do Instituto Adolfo Lutz. São Paulo, SP: Secretaria de Estado da Saúde, 1976. v.1,371 p.

LAL, R.K.; GARG, M.; KRISHNAN, P. S. Biochemical aspects of the developing and ripening banana. Phytochemistry, New York, v.13, n.11, p.2365-2370, 1974.

MORAES, M. A. C. Métodos para a avaliação sensorial dos alimentos. 7.ed. Campinas: Unicamp, 1988. 93p. 
J. L. L. Cultivares. In: ALVES , E. J. (Org.) A cultura da banana: aspectos técnicos, socioeconômicos e agroindustriais. 2.ed. Brasília: Embrapa-SPI / Cruz das Almas: Embrapa-CNPMF, 1999. p. $85-105$.

ROSSIGNOLI, P. A. Atmosfera modificada por filmes de polietileno de baixa densidade com diferentes espessuras para conservação de bananas "Prata" em condições ambiente. Lavras, 80f. Dissertação (Mestrado em Fisiologia), Escola Superior de
Agricultura de Lavras, Lavras, 1983.

SOTO BALLESTERO, M. . Banano - cultivo y comercialización. 2.ed. San José: Litografia e Imprenta LIL, 1992. 674p.

TEIXEIRA, E.; MEINERT, E. M.; BARBETTA, P. A. Análise sensorial de alimentos. Florianópolis: UFSC, 1987. 180p. (Série Didática). 